\title{
MORPHOLOGICAL VARIATIONS IN DUPLICATION OF GREAT SAPHENOUS VEIN
}

\author{
Manisha Vijaywargiya' ${ }^{1}$ Megha Jain ${ }^{2}$, Rashmi Devpujari ${ }^{3}$ \\ ${ }^{1}$ Assistant Professor, Department of Anatomy, L. N. Medical College and Research Centre, Bhopal. \\ ${ }^{2}$ Associate Professor, Department of Radiology, L. N. Medical College and Research Centre, Bhopal. \\ 3 Professor and HOD, Department of Anatomy, People's Medical College and Research Centre, Bhopal.
}

\section{ABSTRACT}

Duplication of Great Saphenous vein is a conduit to varicosity. Knowledge of anatomical and morphological variation in Great Saphenous Vein (GSV) is important for surgeons, orthopaedicians and interventional radiologists who operate in this region and an additional option in coronary artery bypass surgery to avoid iatrogenic varicosity.

\section{AIM}

Cadaveric dissection was done on 30 lower limbs to identify morphologic variations in duplication of GSV.

\section{MATERIALS AND METHODS}

The GSV was dissected from its beginning in front of medial malleolus of ankle to its termination in the upper thigh at the sapheno-femoral junction, where it drains into the femoral vein.

\section{RESULTS}

Seven different forms of duplications were seen in eight of the thirty limbs dissected in our study.

\section{CONCLUSION}

Duplication of the GSV needs to be stressed upon in view of increased incidence of varicosity and cardiovascular diseases and consequent operative intervention.

\section{KEYWORDS}

Great Saphenous Vein, Duplication, Variations, Varicosity, Intervention, Dissection.

HOW TO CITE THIS ARTICLE: Vijaywargiya M, Jain M, Devpujari R. Morphological variations in duplication of great saphenous vein. J. Evolution Med. Dent. Sci. 2016;5(59):4052-4055, DOI: 10.14260/jemds/2016/928

\section{INTRODUCTION}

The venous system is more complex and variable than arterial system due to its frequent anatomical variations. The Great Saphenous Vein (GSV) of the lower limb is the longest superficial vein in the body and liable to as many variations. The normal course of this vein is originating from the medial end of dorsal venous arch in the foot, running upwards anterior to medial malleolus in the superficial fascia at the ankle.(1) continuing cranially along the medial aspect of the calf to posteromedial aspect of the knee. It then continues its course along the medial aspect of thigh before joining femoral vein at fossa ovalis or saphenous opening at the saphenofemoral junction at the level of the groin skin crease. $(2,3)$ Lower limb veins are more prone for venous disorder. The GSV is the most important cause of chronic venous insufficiency in lower limb and leads to complications like subcutaneous oedema, pigmentation and leg ulcers. The frequently met varicose veins and also the utility of the vein as a vessel graft in coronary surgeries make this region of interest for cardiothoracic surgeon and intervention radiologists. Duplication of these veins commonly leads to recurrence of varicose veins, but it also makes the extraction of the vein

Financial or Other, Competing Interest: None.

Submission 17-06-2016, Peer Review 11-07-2016,

Acceptance 18-07-2016, Published 22-07-2016.

Corresponding Author:

Dr. Manisha Vijaywargiya,

Shakuntalam,

E-6/127, Arera Colony,

Bhopal.

E-mail: dollyvijaywargiya@yahoo.co.in

DOI: $10.14260 /$ jemds/2016/928 easier for procedures like coronary artery bypass. Complete knowledge of the variations of GSV is of immense importance in assessment of varicose veins, deep vein thrombosis and venous ulcers. The treatment of varicose veins could be more effective with better success rate, if the knowledge of anatomical variations of the GSV is adequate. Duplication of GSV is one of the potential reasons behind recurrence of varicosity after successful surgery. There are ample radiological evidence on duplications of GSV, but very few cadaveric dissection studies. Our study focuses on the variant morphological presentation met with during the routine dissections of the lower limb.

\section{MATERIAL AND METHODS}

The present study is based on cadaveric dissections done on 30 lower limbs (15 right and 15 left) of embalmed adult cadavers in dissection hall of Anatomy Department of our Medical Institute, i.e. L. N. Medical College and People's Medical College, Bhopal, M.P., India. A superficial dissection was done in the superficial fascia of the lower limb to dissect the GSV from its beginning in front of medial malleolus at ankle to its termination into the femoral vein in the upper thigh region at the saphenous opening. Its tributaries and perforators were also dissected. Photographs of the vein and its variations were taken.

\section{OBSERVATIONS}

The GSV began as the medial end of dorsal venous arch, is joined by medial marginal vein in front of the medial malleolus of the ankle. It took its normal course running on the medial side of the leg, passing behind the medial condyle of tibia and 
femur and then ascending on medial aspect of thigh to open into the common femoral vein by piercing the deep fascia. The vein showed its usual tributaries as mentioned in standard texts of anatomy in the leg and in thigh region. Commonly seen perforators were ankle perforator seen in all limbs, knee perforator in 9 limbs, thigh/adductor canal perforators in 15 limbs. The variations observed in the morphology of the vein were in the form of duplication. The limbs of eight cadavers out of the 30 dissected showed duplication, of which seven different patterns could be elucidated (One of the pattern was common in two cadavers, both were in right limbs and in females, Figure 1) - Thus four patterns were seen in five right limbs and three patterns in three left limb. Of these, four patterns were seen in five females and three in three males.

\section{Following Patterns were Observed}

1. Pattern-1 (Fig. 1): Showed small duplication of GSV at upper thigh region near its termination at saphenofemoral junction in right limb. Two such cases were seen.

2. Pattern-2 (Fig. 2): Showed duplication, which began at the ankle with the two veins joining just above knee to form single GSV in the thigh region in a right limb.

3. Pattern-3 (Fig. 3): Showed duplication of GSV in thigh region, which began in the knee and the two veins united to form single vein just before opening at saphenofemoral junction in right limb in a male cadaver.

4. Pattern-4 (Fig. $\mathbf{4}$ a $\&$ b): The duplication was seen in the right limb in the foot at the formation of GSV, the two joined and reduplicated just above the ankle and then continued in the leg. The two veins joined to form one vein in the thigh region just above the level of knee.

5. Pattern-5 (Fig. 5): Showed duplication in left limb of a male cadaver. The duplication began below knee and the two veins joined to form one vein just before opening into the femoral vein.

6. Pattern-6 (Fig. 6 a \& b): The duplication began around ankle; the two veins formed a mesh-like communication in the upper leg and thigh region. Then they formed two veins in the mid of thigh, which joined to form one vein just before opening into the femoral vein.

7. Pattern-7 (Fig. 7): Showed duplication of GSV in left leg of a female cadaver which began in the ankle region, the two veins united below knee to form one vein which reduplicated at knee level. This duplication ran in the thigh region and the two veins reunited to open as single vein at saphenofemoral junction.

\section{RESULT}

In our study, duplications were seen in eight of the thirty limbs dissected $(26.6 \%)$. These can be further detailed as follows:

- Duplications were present unilaterally.

- Duplications were seen more in thigh region (Six of eight cases).

- Duplications were commoner in females (Five out of eight cases).

- Duplications were commoner in right limb (Five out of eight cases).

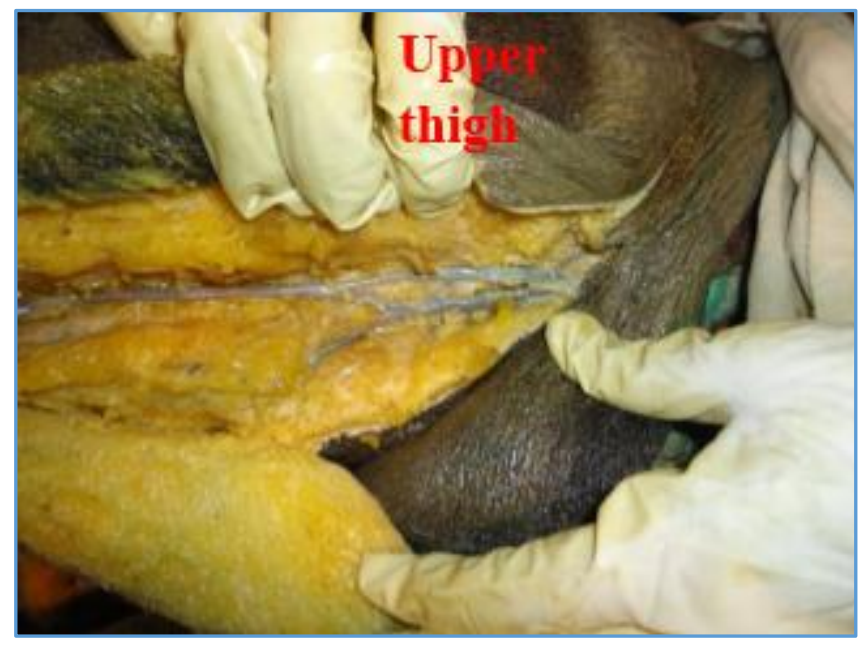

Fig. 1, Pattern-1: Shows Small Duplication in the Upper Thigh Region which Joins to Form Single Vein Opening into Femoral Vein in the Right Limb of a Female Cadaver

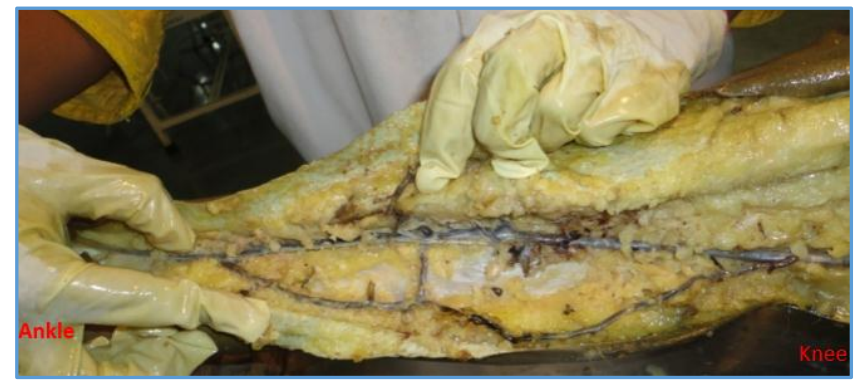

Fig. 2, Pattern-2: Shows Duplication of GSV in Leg Region with a Communication between the Two Veins in the Right Limb of a Female Cadaver

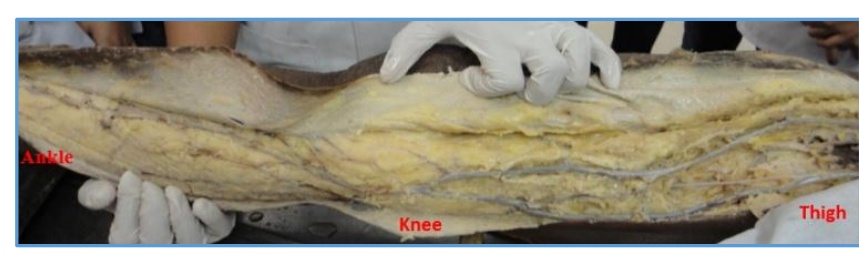

Fig. 3, Pattern-3: Shows Duplication of GSV in Thigh Region Beginning at Knee and the Two Veins Join to Form One Vein Just Before Opening into the Femoral Vein in Right Limb of a Female Cadaver

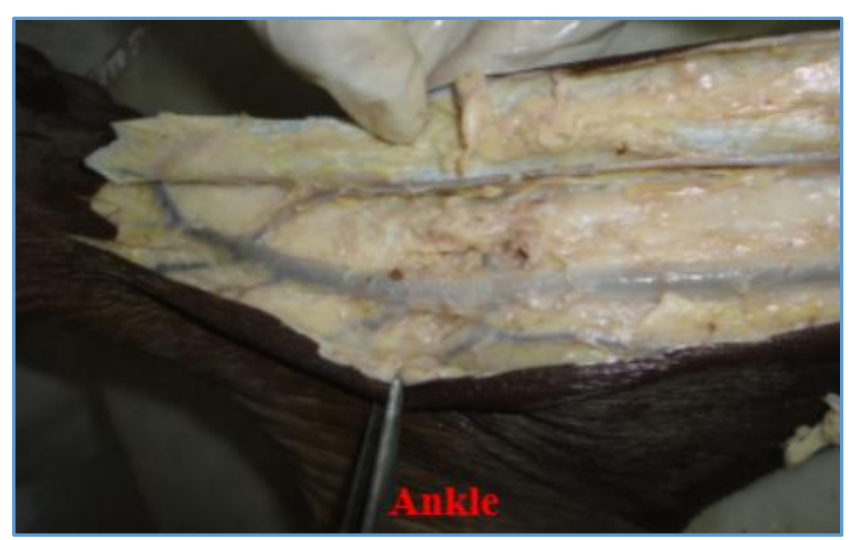

Fig. 4a, Pattern-4 


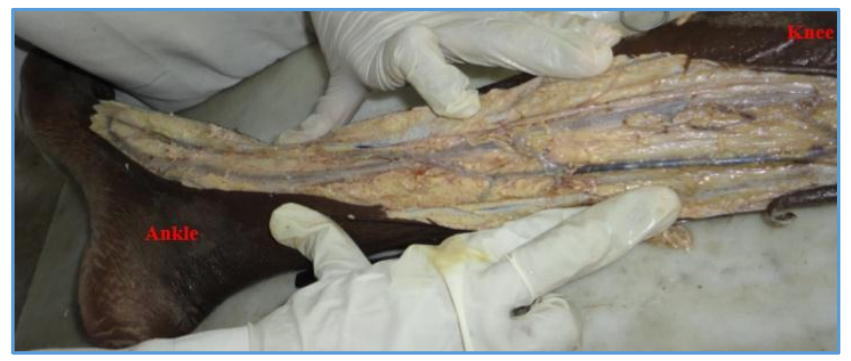

Fig. 4b, Pattern-4

Fig. 4 ( $a$ \& b), Pattern-4: Shows Duplication of GSV Beginning at Foot (Fig. 4a) and Forming One Vein Just Above Ankle, Immediately Reduplicating in Leg Region (Fig. 4 b) and then Forming Single Vein just Above Knee, in Right Limb in a Male Cadaver

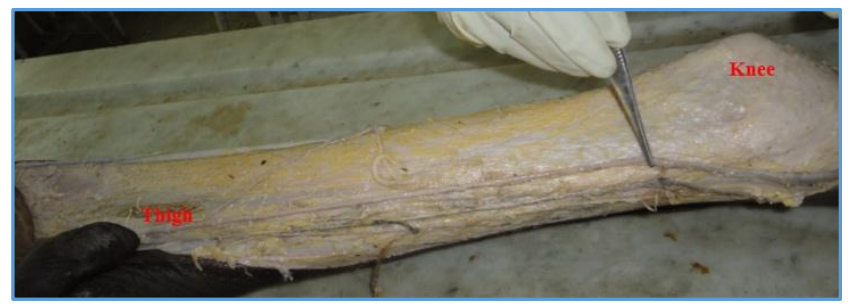

Fig. 5, Pattern-5: Shows Duplication of GSV from Below Knee to its Opening in Femoral Vein in Left Limb of a Male Cadaver

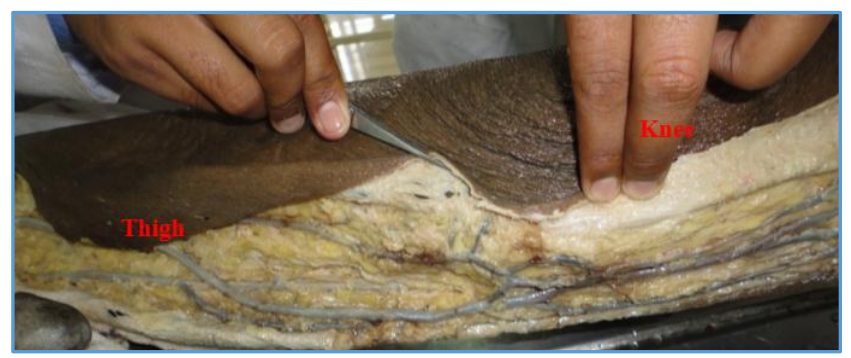

Fig. 6a, Pattern-6

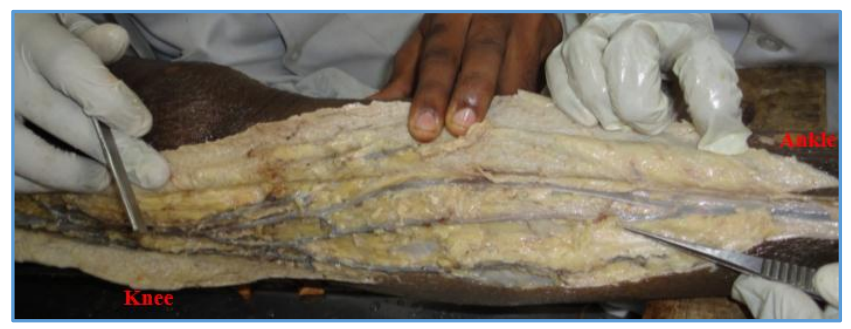

Fig. 6b, Pattern-6

Fig. 6 (a \& b), Pattern-6: Shows Duplication of GSV with Mesh Work in the Thigh Region (Fig. 6a) and Leg Region (Fig. 6b) in Left Limb of a Male Cadaver

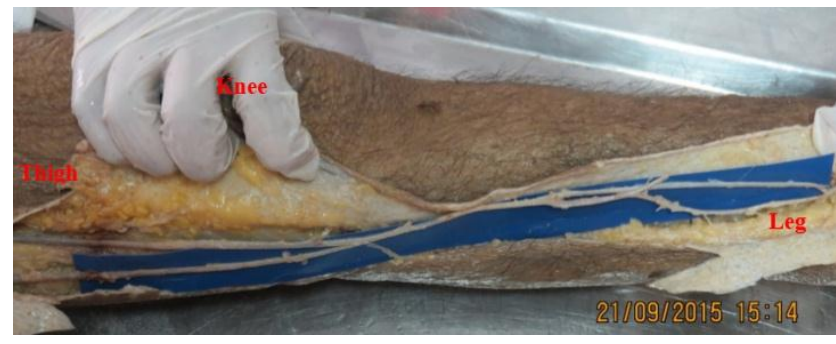

Fig. 7, Pattern 7: Shows Duplication of GSV in Began in the Ankle Region, the Two Veins United Below Knee to Form One Vein which Reduplicated at Knee Level, and the Two Veins Reunited to Open as Single Vein at Saphenofemoral Junction in Left Limb of Female Cadaver

\section{DISCUSSION}

The anatomical texts describe the GSV as a single vein running on the medial side of leg and thigh region.(1,3) Duplication of GSV has been described by the radiologists, while doing saphenograms.(4) or Doppler ultrasonography for varicose veins. There are very few anatomical/cadaveric studies on duplication of GSV and further they are more in the form of case report. Gray has stated the occurrence of duplication of GSV distal to knee.(3) The duplication of GSV is a rare anatomical variation with an incidence of approximately $1 \%$. Various researchers from different countries have reported variable incidence of duplication of great saphenous vein being as high as $49 \%$.

Motwani et al in 2013 reported 8.9\% incidence of duplication of GSV seen in cadaveric study. ${ }^{(5)}$, while it was $20 \%$ by Haythem and Sayigh in Iraq.(6) $9 \%$ by Donnelly.(7) $3 \%$ by Glasser et al(8), while Soames and Talwah have observed 1.3\% duplication of GSV and its association with varicosity.(9)

In ultrasonographic studies, Chen and Prasad have said that duplication of great saphenous vein is rare. They have reported an incidence of $1 \%$ for duplication of great saphenous vein in thigh region.(10) Shah et al found an incidence of $19.41 \%$ duplication of GSV from thigh to calf.(11) Ruoff et al have reported $18 \%$ cases with duplication.(12) and Kockert et al (2012) in a retrospective study by duplex ultrasound and prospective ultrasound reported $1 \%$ to $20 \%$ duplication of GSV, while investigation shows it to be from $1.6 \%$ to $2 \%$.(13) Corrales et al have seen duplication of GSV in 50 of 103 saphenograms, i.e. 49\% incidence and seen it more in the thigh region.(4) An accessory saphenous vein is often mistaken as a duplication of GSV, but accessory vein is usually smaller in size and does not drain the same cutaneous territory. According to them a double saphenous system of entire lower limb is rare with occurrence of $0.97 \%$ (1 of 103 cases). Great saphenous vein duplication is more frequent in males than females, more common unilateral than bilateral and more in the thigh region than in the leg. This is in contrast to our study where duplication is seen more in female cadavers: five female Cadavers and three male. 
The duplications were unilaterally present and in three left and five right limbs. Corrales et al in their radiological study found $48 \%$ duplication of GSV in thigh region, $40 \%$ duplication extending from thigh to calf and $12 \%$ duplication confined to calf. We have seen duplications in 8 of thirty limbs dissected, i.e. an incidence of $26.66 \%$. Duplications seen in our study were 2 in leg (Calf) region and 4 in thigh region; in one case it was in leg and thigh region both and in one case it extended from leg to thigh region forming a mesh. Some patterns seen in our study had resemblance to a few case reports by various researchers. Pattern-3 is similar to a case report mentioned by Manisha et al who observed unilateral duplication of great saphenous vein in a male cadaver in the right lower limb below knee at level of medial condyle of Tibia. In our study, similar duplication was seen in left leg in a female cadaver. Both GSVs lie in the same cutaneous plane parallel to the skin and run along the aponeurotic deep fascia. These two GSVs also have same calibre and drain a common cutaneous territory.(14)

Pattern- 6 of our study resembles somewhat to the case reported by Siri et al.(15) They found the duplication of great saphenous vein in the right lower limb. The duplication began from its origin near medial malleolus till the knee joint where it was joined by a tributary and later in the lower one-third of the thigh it branched like a mesh and formed three trunks which ascended in the thigh and in the upper one-third of the thigh two trunks joined to form anterior accessory saphenous vein and great saphenous vein proper, which emptied into the femoral vein by piercing the cribriform fascia. In our study we found duplication began around ankle, the two veins formed a mesh-like communication in the upper leg and thigh region. Then they formed two veins in the mid of thigh, which joined to form one vein just before opening into the femoral vein. The duplication of great saphenous vein explains its recurrent incompetence. Also presence of such accessory trunks can be used for vascular grafting in cases of ischaemia and arterial blocks.

\section{CONCLUSION}

The Duplication of the GSV needs to be stressed upon in view of increased incidence of varicosity and cardiovascular diseases and consequent operative intervention. GSV has several patterns of duplication, and knowledge of these patterns is necessary for both surgeons and intervention radiologists.

\section{REFERENCES}

1. Sinnatamby CS. Lower limb. Last's anatomy-regional and applied. 11 $11^{\text {th }}$ ed. Edinburgh: Churchill Livingstone Elsevier 2006:117-8.
2. Snell RS. The lower limb. Clinical anatomy by regions. $8^{\text {th }}$ ed. Philadelphia: Lippincott Williams \& Wilkins 2008:570-2.

3. Standring S, Mahadevan V, Lee J, et al. Pelvic girdle, gluteal region and thigh. In: Standring S, ed. Gray's anatomy. $40^{\text {th }}$ ed. Edinburgh: Churchill Livingstone Elsevier 2009:1381.

4. Corrales NE, Irvine A, McGuiness CL, et al. Incidence and pattern of long saphenous vein duplication and its possible implications for recurrence after varicose vein surgery. British Journal of Surgery 2002;89(3):323-6.

5. Motwani R, Jain P. Duplication of great saphenous veinanatomical description and its clinical implications. International Journal of Biological \& Medical Research 2013;4(3):3372-4.

6. Haythem A, Al-Sayigh. The incidence of double great saphenous vein among Iraqi people a: case series study. Medical Journal of Babylon 2014;6:2.

7. Donnelly M, Tierney S, Feeley TM. Anatomical variation at the sapheno femoral junction. Br J Surg 2005;92(3): 322-5.

8. Glasser ST. Variations of the tributaries of the saphena magna at the sapheno-femoral junction: abstract of demonstration. Anat Rec 1942;82:289-95.

9. Talwah WAl, Soames R. A duplicated great saphenous vein and clinical significance for varicosity. Rev Arg De Anat Clin 2014;6(1);43-6.

10. Su-Hsin CS, Prasad SK. Long saphenous vein and its anatomical variations. AJUM 2009;12(1):28-31.

11. Shah DM, Chang BB, Leopold PW, et al. The anatomy of the greater saphenous venous system. Journal of Vascular Surgery 1986;3(2):273-83.

12. Ruoff BA, Cranley JJ, Hannan LA, et al. Real-time duplex ultrasound mapping of the greater saphenous vein before in situ infra-inguinal revascularization. J Vasc Surg 1987;6(2):107-13.

13. Kockaert M, de Ross KP, Dijk VL, et al. Duplication of the great saphenous vein: a definition problem and implications for therapy. Dermatol Surg 2012;38(1): 77-82.

14. Nakhate MS, Ghoshal J, Sawant VG. A rare variation of great saphenous vein. Journal of Evolution of Med and Dent Sci 2014;3(61):13625-7.

15. Siri AM, Ravikumar V, Sadashivana GH, et al. Duplication of great saphenous vein-a rare occurrence. International Journal of Contemporary Medicine 2013;1(1):55-7. 